\title{
Spectral Properties of Leaves Deficient in Iron, Sulfur, Magnesium, and Manganese
}

\author{
Alessandro Masoni,* Laura Ercoli, and Marco Mariotti
}

\begin{abstract}
In crop plants, deficiency of an essential element may drastically reduce growth rate and yield. Research on the use of leaf spectral properties in the detection of crop mineral deficiency is needed. The objective of this study was to examine the effects of $\mathrm{Fe}, \mathrm{S}, \mathrm{Mg}$, and Mn deficiency on reflectance (R), absorptance (A), and transmittance (T) spectra of barley (Hordeum vulgare $\mathrm{L}$.), wheat (Triticum aestivum L.), corn (Zea mays L.), and sunflower (Helianthus annuus L.) leaves. Plants were grown in the greenhouse in nutrient solution. Chlorophyll (Chl), $\mathrm{Fe}, \mathrm{S}, \mathrm{Mg}$, and $\mathrm{Mn}$ concentrations and spectral properties were determined on the youngest fully expanded leaf when deficiency symptoms were clearly manifested. In all species, mineral deficiency affected leaf concentration of the deficient element and also of other elements. Nutrient deficiency reduced $\mathrm{Chl}$ concentration and $\mathrm{A}$, and increased $\mathbf{R}$ and $\mathbf{T}$. Iron deficiency severely affected all species, and corn was the species most sensitive to all deficiencies. Reflectance, A, and $\mathrm{T}$ spectra of leaves were correlated with leaf $\mathrm{Chl}$ concentration. Our results suggested that all nutritional deficiencies reduce leaf $\mathrm{Chl}$ concentration, and subsequently this reduction increases leaf $\mathbf{R}$ and $T$, decreases leaf $\mathbf{A}$, and shortens the red-edge position, defined as the inflection point that occurs in the rapid transition between red and near-infrared. Modifications in leaf spectral properties were not characteristic of nutrient deficiency, but were always observed in the same wavelengths.
\end{abstract}

$\mathrm{D}$ EICIENCY OF AN ESSENTIAL ELEMENT may drastically reduce growth rate and yield in crop plants. Mineral deficiency causes visible abnormalities in pigmentation, size, and shape of leaves and leaf photosynthetic rate, also leading to the appearance of various other symptoms. Leaf photosynthetic rate is linked to the amount of absorbed radiation, which depends on incident radiation and leaf absorptance. Absorptance is affected by leaf external and internal reflectance and by leaf pigment content, essentially represented by chlorophyll (Maas and Dunlap, 1989).

Several authors have found empirical relationships between leaf spectral properties and leaf morphological and physiological conditions, including leaf thickness (Gausman and Allen, 1973), presence of pubescence (Nielsen et al., 1984), $\mathrm{N}$ content (Walburg et al., 1982), water content (Gausman et al., 1971), and chlorophyll concentration (Gausman, 1982; Ercoli et al., 1993). Other studies have documented spectral and morphological changes in plants grown with abnormal concentrations of mineral elements in the nutrient solution. Al-Abbas et al. (1974) showed that corn plants growing under N-,

A. Masoni and M. Mariotti, Dip. di Agronomia e Gestione dell'AgroEcosistema, Univ. of Pisa, via S. Michele degli Scalzi 2, 56100 Pisa, Italy; L. Ercoli, Scuola Superiore di Studi Universitari e di Perfezionamento S. Anna, via Carducci 40, 56100 Pisa, Italy. Received 27 Nov. 1995. *Corresponding author.

Published in Agron. J. 88:937-943 (1996).
Mg-, S-, K-, P-, and Ca-deficient conditions had higher leaf $\mathrm{R}$ and $\mathrm{T}$ and lower $\mathrm{A}$ in the visible region of the spectrum $(400-700 \mathrm{~nm})$ than normal plants. Milton et al. $(1989,1991)$ studied spectral reflectance in Hosta ventricosa $\mathrm{Co}^{-}, \mathrm{Ni}^{-}$, and $\mathrm{Zn}$-deficient plants, and in soybean [Glycine $\max (\mathrm{L}$.$) Merr.] As-, P-, and Se-$ deficient plants. They showed that, with lower than normal $\mathrm{Co}, \mathrm{Ni}, \mathrm{Zn}, \mathrm{As}$, and $\mathrm{P}$ content, $\mathrm{R}$ increased in the 500- to $650-\mathrm{nm}$ portion of the spectrum and the red edge (the inflection point that occurs in the rapid transition between red and near-infrared; Horler et al., 1983) shifted to shorter wavelengths. In contrast, Se-dosed soybean plants displayed virtually opposite results. Furthermore, in studies by Thomas and Oerther (1972) on sweet pepper (Capsicum annuum L.) it was found that leaf $\mathrm{R}$ increased with decreasing leaf $\mathrm{N}$ content. Adams et al. (1993), reporting on soybean, showed that a decrease in leaf $\mathrm{Mn}$ concentration led to an increase in $\mathrm{R}$ and shifted the red-edge position to shorter wavelengths. However, use of spectral properties as a diagnostic tool in nutrient deficiency diagnosis requires further understanding of the relationship between spectral properties and nutrient concentration in plant tissue. Aspects of this relationship have been described for corn with varying $\mathrm{N}$ fertilizer levels (Ercoli et al., 1993; Blackmer et al., 1994).

Our objective was to examine the effects of $\mathrm{Fe}, \mathrm{S}, \mathrm{Mg}$, and $\mathrm{Mn}$ deficiency on mineral and $\mathrm{Chl}$ concentrations and on $\mathrm{R}, \mathrm{A}$, and $\mathrm{T}$ spectra of attached leaves of barley, wheat, corn, and sunflower. In addition, this study assessed whether nutrient deficiency produces changes in detailed curve shape that could be used diagnostically for detection of the deficiency itself.

\section{MATERIALS AND METHODS}

Research was carried out in 1993 at the Department of Agronomy and Agroecosystem Management (Agronomia e Gestione dell'Agro-Ecosistema), University of Pisa, Italy. 'Aura' distichous barley (Hordeum vulgare L.), 'Pandas' winter wheat (Triticum aestivum L.), hybrid Laurus corn (Zea mays L.), and hybrid Oleica sunflower (Helianthus annuus L.) were grown on nutrient solution in the greenhouse. These four species, which are among the most widely cultivated crops in Italy, were chosen with the aim of ascertaining the effects of mineral deficiency in leaves of plants with similar or different botanical characteristics. For each species, treatments consisted of five different nutrient culture solutions, as follows: complete solution, minus $\mathrm{Fe}$, minus $\mathrm{S}$, minus $\mathrm{Mg}$, and minus $\mathrm{Mn}$.

Three seeds per species were sown in plastic pots $(6 \mathrm{~cm}$ deep, $6 \mathrm{~cm}$ diam.) filled with agriperlite. The sowing date was 5 January for barley and wheat and 5 March for corn and sunflower. After germination, seedlings were thinned to

Abbreviations: A, absorptance; Chl, chlorophyll; NIR, near-infrared radiation; $R$, reflectance; $T$, transmittance. 
Table 1. Phenological stage and days after emergence (DAE) of visible deficiency symptoms, degree of chlorosis (DOC), and nodal position of measured leaves (ML) from barley, wheat, corn, and sunflower plants grown under normal and $\mathrm{Fe}-, \mathrm{S}-, \mathrm{Mg}-$, and Mn-deficient conditions. $\dagger$

\begin{tabular}{|c|c|c|c|c|c|c|}
\hline \multirow[b]{2}{*}{ Crop } & \multirow[b]{2}{*}{ Deficiency } & \multicolumn{2}{|c|}{ Stage of deficiency evidence } & \multirow[b]{2}{*}{ DAE } & \multirow[b]{2}{*}{ ML } & \multirow[b]{2}{*}{ DOC } \\
\hline & & Reference scale $\ddagger$ & Description & & & \\
\hline Barley & $\begin{array}{l}\text { Normal-1§ } \\
\text { Fe } \\
\text { Normal-2 } \\
\text { S } \\
\text { Mg } \\
\text { Mn }\end{array}$ & $\begin{array}{l}32 \\
32 \\
43 \\
43 \\
43 \\
43\end{array}$ & $\begin{array}{l}\text { 2nd node detectable } \\
\text { 2nd node detectable } \\
\text { Boots just visibly swollen } \\
\text { Boots just visibly swollen } \\
\text { Boots just visibly swollen } \\
\text { Boots just visibly swollen }\end{array}$ & $\begin{array}{l}75 \\
75 \\
85 \\
85 \\
85 \\
85\end{array}$ & $\begin{array}{l}5 \\
5 \\
6 \\
6 \\
6 \\
6\end{array}$ & $\begin{array}{l}\text { None } \\
\text { Moderate } \\
\text { None } \\
\text { Slight } \\
\text { Slight } \\
\text { Slight }\end{array}$ \\
\hline Corn & $\begin{array}{l}\text { Normal-1 } \\
\mathrm{Fe} \\
\mathrm{S} \\
\text { Normal-2 } \\
\mathrm{Mg} \\
\mathrm{Mn}\end{array}$ & $\begin{array}{l}1 \\
1 \\
1 \\
1 \\
1 \\
1\end{array}$ & $\begin{array}{l}4 \text { leaves } \\
4 \text { leaves } \\
4 \text { leaves } \\
5 \text { leaves } \\
5 \text { leaves } \\
5 \text { leaves }\end{array}$ & $\begin{array}{l}29 \\
29 \\
29 \\
45 \\
45 \\
45\end{array}$ & $\begin{array}{l}3 \\
3 \\
3 \\
4 \\
4 \\
4\end{array}$ & $\begin{array}{l}\text { None } \\
\text { Severe } \\
\text { Moderate } \\
\text { None } \\
\text { Moderate } \\
\text { Moderate }\end{array}$ \\
\hline
\end{tabular}

† For all species and deficiency treatments (with one exception), initial symptoms of mineral deficiency occurred on the youngest leaf; for Mg deficiency on sunflower, initial symptoms occurred on the oldest leaf.

$\ddagger$ Phenological stages are according to Zadoks et al. (1974) for barley and wheat, Hanway (1963) for corn, and Schneiter and Miller (1981) for sunflower. $\S$ Normal-1, -2, and -3 differ only by phenological stage (matching that of the nutrient-deficient plants), not in nutrient solution.

one per pot and 160 pots were placed on $0.7 \mathrm{~m}^{2}$ ( 1.2 by 0.6 m) plastic trays containing the nutrient solutions, with one species per tray. Basic composition of the nutrient solution followed Clark (1982) (in mg L ${ }^{-1}$ ): $\mathrm{NO}_{3}-\mathrm{N}, 321 ; \mathrm{Ca}, 302$; $\mathrm{K}, 283 ; \mathrm{Cl}, 65 ; \mathrm{S}, 58.5 ; \mathrm{NH}_{4}-\mathrm{N}, 39 ; \mathrm{Mg}, 37.8 ; \mathrm{Na}, 4.56$; Fe, 4; P, 2; Mn, 0.974; B, 0.536; Zn, 0.3; Cu, 0.076; Mo, 0.155 . Growth solution was changed every $3 \mathrm{~d}$ and $\mathrm{pH}$ was adjusted daily to 6.5 with $\mathrm{HNO}_{3}$ or $\mathrm{NaOH}$. Deionized water was used throughout the experiment and added as needed to maintain solution volume.

All measurements were performed on the youngest fully expanded leaf when leaf mineral deficiency symptoms were clearly manifested. For each species, three leaves (one per plant) randomly selected from each nutrient solution deficiency were compared with three leaves from the control at the same phenological stage as the deficient plants, so that the comparison was made on leaves in the same nodal position. According to Berg et al. (1993), degree of chlorosis of the measured leaf was visually rated as follows: none, slight (10 to $30 \%$ interveinal chlorosis), moderate (30 to $100 \%$ interveinal chlorosis and veins green), severe (entire leaf chlorotic), and very severe (leaf nearly white with necrotic tip).

Reflected and transmitted radiation spectra of adaxial (upper) surfaces of attached leaves were measured using a LI-COR (Lincoln, NE) portable spectroradiometer, Model LI-1800, connected to an external integrating sphere by means of a quartz fiber-optic probe. Measurements were taken over the wavelength range from 400 to $1100 \mathrm{~nm}$ at a scanning interval of $1 \mathrm{~nm}$. The integrating sphere included a 10-W glass halogen lamp as radiation source and a pressed barium sulfate $\left(\mathrm{BaSO}_{4}\right)$ reference standard. For all species, measurements were taken from an area measuring roughly $1.8 \mathrm{~cm}^{2}$ (sample port) situated at the center of the right-hand leaf lamina. Reflectance and transmittance were calculated as the ratio of reflected radiation from and transmitted radiation through the sample surface to reflected and transmitted radiation from the standard and expressed in percent. Absorptance was computed as: $A=100$ $-(R+T)$. The inflection point that occurs in the rapid transition between red and near-infrared, termed the red edge, is thought useful in estimating leaf pigment content, discriminating crop type and maturity, and estimating the severity of stress and crop condition (Horler et al., 1983). First derivatives of the $\mathrm{R}, \mathrm{A}$, and $\mathrm{T}$ individual spectral curves between 678 and $740 \mathrm{~nm}$ were computed, and the inflection points (maxima on the first-derivative spectra) were used to define the position of the edge. The derivative spectrum was calculated by fitting a third-order polynomial into the data with the least squares method as suggested by Savitzky and Golay (1964).

Immediately following spectroradiometric measurements, leaf area, fresh and dry weight, and Chl $a$ and $b$ concentrations were determined. Leaf area was measured using an image analyzer (Leica Quantimet 500). Ten $50-\mathrm{mm}^{2}$ disk samples were collected from each leaf for Chl determination. Disks were placed in a test tube, stoppered and deep-frozen (using dry ice) for transport to the laboratory, and then stored at $-18^{\circ} \mathrm{C}$ until $\mathrm{Chl}$ analysis. Absorptance of $N, N$-dimethylformamide leaf sample extract was measured at 664 and 647 $\mathrm{nm}$ on a spectrophotometer (Lambda 6 UV/VIS, Perkin-Elmer, Norwalk, CT) using cuvettes of $10-\mathrm{mm}$ path length. Chlorophyll $a$ and $b$, expressed in moles on leaf area basis, were determined according to the Moran (1982) formulae.

Leaves from 60 plants (one leaf per plant) were combined in three samples (replications) for $\mathrm{Fe}, \mathrm{S}, \mathrm{Mg}$, and $\mathrm{Mn}$ analysis. Samples were ground to pass through a 40-mesh stainless steel screen. For $\mathrm{Fe}, \mathrm{Mg}$, and $\mathrm{Mn}$ analysis, samples $(0.5 \mathrm{~g})$ were wet-ashed by overnight predigestion in $14 \mathrm{~mL}$ of concentrated $\mathrm{HNO}_{3}-\mathrm{HClO}_{4}$ mixture (5:2 v/v basis) and digestion was completed in an aluminum block heater at $205^{\circ} \mathrm{C}$ (Ohki, 1984). Ashed extracts were brought to $25 \mathrm{~mL}$ volume and $\mathrm{Fe}, \mathrm{Mg}$, and $\mathrm{Mn}$ were determined by atomic absorption spectrometry 
Table 2. Iron, S, Mg, and Mn concentration of the youngest fully expanded leaf of barley, wheat, corn, and sunflower plants grown under normal and Fe-, S-, Mg-, and Mn-deficient conditions. For each species and deficiency, comparison was made between leaves grown under normal and mineral-deficient conditions.

\begin{tabular}{|c|c|c|c|c|c|c|c|c|}
\hline \multirow[b]{3}{*}{ Crop } & \multicolumn{8}{|c|}{ Mineral concentration (by growth medium treatment) } \\
\hline & \multicolumn{2}{|c|}{$\mathrm{Fe}$} & \multicolumn{2}{|c|}{$\mathrm{S}$} & \multicolumn{2}{|c|}{$\mathrm{Mg}$} & \multicolumn{2}{|c|}{ Mn } \\
\hline & Normal & Deficient & Normal & Deficient & Normal & Deficient & Normal & Deficient \\
\hline Barley & 72 & $41^{*}$ & 94 & $47 *$ & 94 & $63^{*}$ & 94 & 77 \\
\hline Wheat & 60 & $39 *$ & 85 & 76 & 85 & $71^{*}$ & 85 & $60^{*}$ \\
\hline Corn & 82 & $32 *$ & 82 & $28^{*}$ & 115 & $40^{*}$ & 115 & $44^{*}$ \\
\hline \multirow[t]{2}{*}{ Sunflower } & 65 & $39 *$ & 142 & $90^{*}$ & 179 & $96^{*}$ & 179 & $117^{*}$ \\
\hline & \multicolumn{8}{|c|}{$\underline{\text { Sulfur, } \mathrm{mmol} \mathrm{m}^{-2}}$} \\
\hline Barley & 8.9 & 9.0 & 10.9 & $8.9 *$ & 10.9 & 10.9 & 10.9 & $8.7^{*}$ \\
\hline Wheat & 6.0 & 6.1 & 10.4 & $8.5^{*}$ & 10.4 & 10.4 & 10.4 & $8.0 *$ \\
\hline Corn & 6.2 & $3.9 *$ & 6.2 & $4.9 *$ & 6.2 & $3.7 *$ & 6.2 & $3.5^{*}$ \\
\hline \multirow[t]{2}{*}{ Sunflower } & 6.4 & 5.5 & 11.3 & $6.3^{*}$ & 11.4 & $7.0^{*}$ & 11.4 & $6.6^{*}$ \\
\hline & \multicolumn{8}{|c|}{ Magnesium, $\mathrm{mmol} \mathrm{m}^{-2}$} \\
\hline Barley & 2.5 & $3.4 *$ & 2.8 & $1.9 *$ & 2.8 & $0.9^{*}$ & 2.8 & $2.0^{*}$ \\
\hline Wheat & 2.5 & $3.4^{*}$ & 3.3 & $2.4^{*}$ & 3.3 & $0.7^{*}$ & 3.3 & $1.8^{*}$ \\
\hline Wheat & 15 & $26^{*}$ & 17 & $8^{*}$ & 17 & $5^{*}$ & 17 & $2^{*}$ \\
\hline Corn & 38 & $27 *$ & 38 & $27 *$ & 50 & $39 *$ & 50 & $25^{*}$ \\
\hline Sunflower & 17 & $50 *$ & 33 & $13 *$ & 42 & $30 *$ & 42 & $7 *$ \\
\hline
\end{tabular}

* Significant at the 0.05 probability level $(F$-test $)$.

(Zeiss FMD3 spectrophotometer). For total S assay, following Hafez et al. (1991), $0.2 \mathrm{~g}$ of plant material was digested with $2 \mathrm{~mL}$ of concentrated $\mathrm{HNO}_{3}$ containing $1.25 \mathrm{~g} \mathrm{~L}^{-1} \mathrm{MgO}$ and $1 \mathrm{~mL}$ of $70 \%(\mathrm{v} / \mathrm{v}) \mathrm{HClO}_{4}$ and subsequently evaporated to dryness. Ashed extract was supplemented with $5 \mathrm{~mL}$ of 250 $\mathrm{m} M \mathrm{NaOH}$ and brought to $50 \mathrm{~mL}$ volume. The liquid was filtered through a $0.45-\mu \mathrm{m}$ filter and the filtrate was analyzed for $\mathrm{SO}_{4}-\mathrm{S}$ using an ion-chromatograph.

Since in the various species deficiency symptoms were detected at different stages and on leaves of different nodal position, analysis of variance was performed separately for each species and growth-medium deficiency to test the significance of the difference between control and individual mineral deficiency. Statistical analysis on spectral data was undertaken as bands of $10 \mathrm{~nm}$ width in the spectral range from 400 to $1100 \mathrm{~nm}$.

Analysis of correlation was performed to assess the relationships between leaf spectral properties at the 429-, 555-, 678-, and $700-\mathrm{nm}$ wavelengths and in the visible region and leaf Chl $a$ and $b$ concentration. These wavelengths were chosen because at 429 and $678 \mathrm{~nm}$ maximum in vivo Chl absorption occurred and at 555 and $700 \mathrm{~nm}$ the highest variations produced by mineral deficiencies were recorded. The model used to represent the relationship between leaf spectral properties $(y)$ and Chl was $y=a[1+b \exp (-k x)]$, where $x$ is leaf Chl concentration expressed in moles per unit area (Ercoli et al., 1993). In the model, the expression $\exp (-k x)$ represents radiation attenuation within the leaf that decreases exponentially with increasing leaf thickness $(x)$ on the basis of a specific extinction coefficient $k$. In the leaf, chlorophyll is the substance having the greatest effect on $\mathrm{A}$ in the visible region; therefore, the assumption was made that its content, expressed in moles per unit leaf area $(x)$, would adequately represent leaf thickness. In the model, the coefficient $b$ represents the percentage increase (for $\mathrm{R}$ and $\mathrm{T}$ ) or decrease (for A) of the value of $a$ with $x=0$ and $(a b)$ represents the range of values assumed by $y$ with progressive increase of $x$ from 0 to infinity $(a b=$ $\left.y_{\max }-y_{\min }\right)$.

\section{RESULTS AND DISCUSSION Leaf Symptoms of Mineral Deficiency}

The degree of chlorosis and the stage at which leaf symptoms of mineral deficiency were detected varied among species and mineral deficiencies (Table 1). Corn was found to be the most sensitive to all deficiencies, as in this plant symptoms were evident as early as the 4- to 5-leaf stage. In all species, Fe- and S-deficiency symptoms occurred in early growth stages while $\mathrm{Mg}$ and Mn-deficiency symptoms occurred at early stages in corn and later in barley, wheat, and sunflower. Iron deficiency produced moderate or severe chlorosis at early stages in all species. Symptoms of Mg deficiency were slight in barley and wheat leaves and moderate in corn and sunflower leaves; symptoms of $\mathrm{Mn}$ - and S-deficiencies were slight in barley, wheat, and sunflower leaves and moderate in corn leaves.

\section{Leaf Mineral Concentration}

In all species, $\mathrm{Fe}, \mathrm{S}, \mathrm{Mg}$, and $\mathrm{Mn}$ deficiency in growth medium greatly decreased leaf concentration of the respective deficient element, although not all differences were significant (Table 2). Accumulation of other elements in leaves also varied with the different availability of any of the elements, indicating that deficient supply of any given mineral element may limit uptake of other elements, but correlations among leaf concentrations of elements were not observed.

Deficiency of a given mineral element may produce biochemical disorders that modify accumulation of other elements, thereby increasing or decreasing concentration as compared with normal nutritional conditions. Thus, deficiency symptoms and morphological and physiologi- 
cal modifications may not be produced by or characteristic of one deficient element, but may instead be produced by combined deficiency of more than one element, although all reduced mineral concentrations are caused by deficiency of only one element in the growth medium. In corn, for example, $\mathrm{S}$ deficiency caused a greater percent reduction in leaf $\mathrm{Fe}$ concentration (by $66 \%$ ) than in leaf $\mathrm{S}$ concentration (by $21 \%$ ).

\section{Leaf Chlorophyll Concentration}

Growth-medium mineral deficiencies decreased leaf Chl $a$ and $b$ concentration of all species by a percentage that differed according to species and mineral, ranging from 10 to $80 \%$ of the corresponding control (Table 3 ). Corn was the crop most sensitive to nutrient deficiency, as Chl $a$ concentration of leaves from plants grown under $\mathrm{Fe}-, \mathrm{Mg}-$, and $\mathrm{Mn}$-deficient conditions was $22 \%$ of the control, and that under S-deficient conditions was approximately $50 \%$. In barley and wheat, the highest reduction in $\mathrm{Chl}$ was induced by $\mathrm{Fe}$, followed by $\mathrm{S}$ and $\mathrm{Mg}$, while $\mathrm{Mn}$ produced the least effect. Sunflower leaf $\mathrm{Chl} a$ concentration decreased to approximately $60 \%$ of normal values in plants grown under $\mathrm{Mg}-, \mathrm{Mn-}$, and S-deficient conditions and to $23 \%$ in Fe-deficient plants. Mineral deficiencies decreased leaf $\mathrm{Chl} b$ concentration differently from Chl $a$ concentration.

The leaf $\mathrm{Chl} a / b$ ratio increased significantly only in leaves of $\mathrm{Mg}$-deficient wheat and decreased significantly in leaves of corn with all deficiencies, of sunflower with Fe deficiency, and of barley and wheat with S deficiency.

No correlation was observed between leaf Chl $a$, and $b$ concentration and leaf $\mathrm{Fe}, \mathrm{Mg}, \mathrm{Mn}$, and $\mathrm{S}$ concentration. This result indicates that, although in all species growthmedium mineral deficiencies reduced leaf $\mathrm{Chl}$ concentration, such a reduction is not equal among species, because of differences in microelement requirements among the various species.
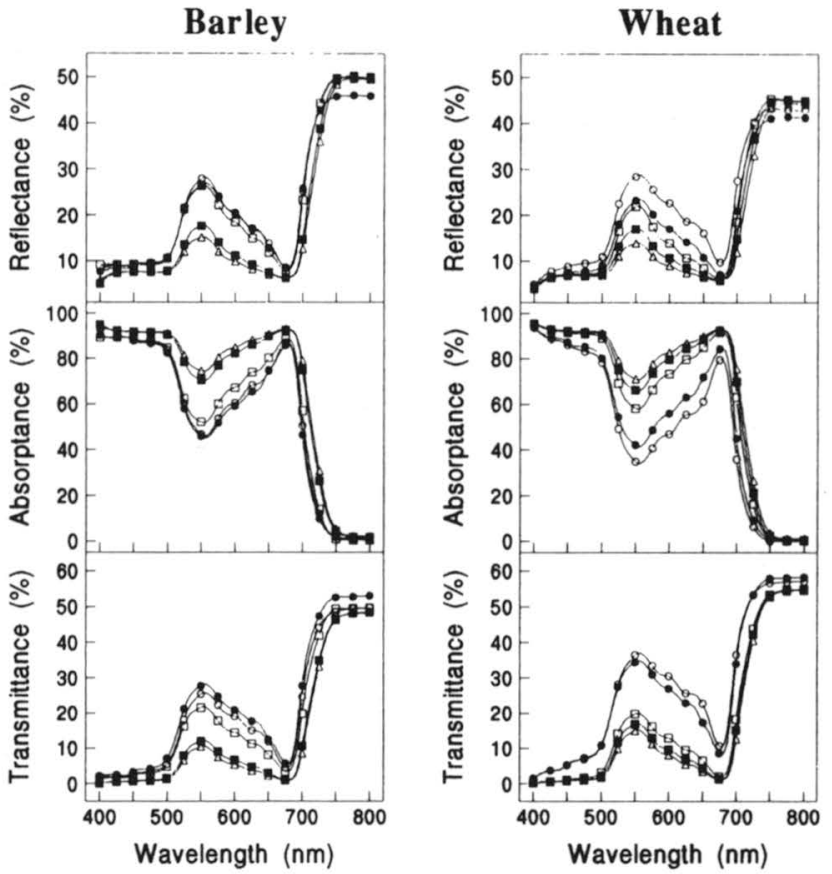

Fig. 1. Spectra of $\mathbf{R}, \mathbf{A}$, and $\mathrm{T}$ of the youngest fully expanded leaf of barley and wheat. Legend: open triangles, normal plants; open circles, Fe; solid circles, $\mathrm{S}$; open squares, $\mathbf{M g}$; solid squares, $\mathrm{Mn}$.

\section{Reflectance, Absorptance, and Transmittance}

Figures 1, 2, and 3 illustrate R, A, and T spectra between 400 and $800 \mathrm{~nm}$ recorded for all species and growth media. In all cases, A decreased markedly from 400 to a minimum at $555 \mathrm{~nm}$, then increased from 555 to $678 \mathrm{~nm}$. Through the near-infrared (NIR) region, A decreased to a minimum at $750 \mathrm{~nm}$. Beyond $750 \mathrm{~nm}$, A remained practically constant at about $2 \%$. Reflectance and $\mathrm{T}$ spectra were opposite to that of $\mathrm{A}$, with a local maximum at 555 and $750 \mathrm{~nm}$ and a local minimum at 500 and $678 \mathrm{~nm}$. Values of R, A, and T at 555 and 700 $\mathrm{nm}$ were similar and, as shown also by Chappelle et al.

Table 3. Chlorophyll $a$ and $b$ concentration and $\mathrm{Chl} a / b$ ratio of the youngest fully expanded leaf of barley, wheat, corn, and sunflower plants grown under normal and $\mathrm{Fe}-, \mathrm{S}-, \mathrm{Mg}-$, and $\mathrm{Mn}$-deficient conditions. For each species and deficiency, comparison was made between leaves grown under normal and mineral deficient conditions.

\begin{tabular}{|c|c|c|c|c|c|c|c|c|}
\hline \multirow[b]{3}{*}{ Crop } & \multicolumn{8}{|c|}{ Chlorophyll $a$ and $b$ concentration and ratio (by growth medium treatment) } \\
\hline & \multicolumn{2}{|c|}{$\mathrm{Fe}$} & \multicolumn{2}{|c|}{$\mathrm{S}$} & \multicolumn{2}{|c|}{$\mathrm{Mg}$} & \multicolumn{2}{|c|}{ Mn } \\
\hline & Normal & Deficient & Normal & Deficient & Normal & Deficient & Normal & Deficient \\
\hline Barley & 457 & $165^{*}$ & 448 & $127 *$ & 448 & 196* & 448 & $357^{*}$ \\
\hline Wheat & 401 & 99* & 433 & $148^{*}$ & 433 & $274^{*}$ & 433 & $354^{*}$ \\
\hline Corn & 259 & 28* & 259 & $128^{*}$ & 437 & $56^{*}$ & 437 & 97* \\
\hline Sunflower & 256 & $58^{*}$ & 408 & $242^{*}$ & 443 & $210^{*}$ & 443 & $286^{*}$ \\
\hline Barley & 149 & 50 * & 139 & $73 *$ & 139 & $62 *$ & 139 & $115^{*}$ \\
\hline Wheat & 113 & $31^{*}$ & 137 & $72 *$ & 137 & $77 *$ & 137 & $112 *$ \\
\hline Corn & 92 & $38^{*}$ & 92 & $66^{*}$ & 131 & $27^{*}$ & 131 & $39^{*}$ \\
\hline \multirow[t]{2}{*}{ Sunflower } & 81 & $27 *$ & 149 & $90^{*}$ & 160 & $72 *$ & 160 & $94^{*}$ \\
\hline & \multicolumn{8}{|c|}{ Chl $a / b$} \\
\hline Barley & 3.1 & 3.3 & 3.2 & $1.7^{*}$ & 3.2 & 3.1 & 3.2 & 3.1 \\
\hline Wheat & 3.6 & $3.2 *$ & 3.2 & $2.1^{*}$ & 3.2 & $3.6^{*}$ & 3.2 & 3.2 \\
\hline
\end{tabular}

* Significant at the 0.05 probability level $(F$-test). 


\section{Corn}

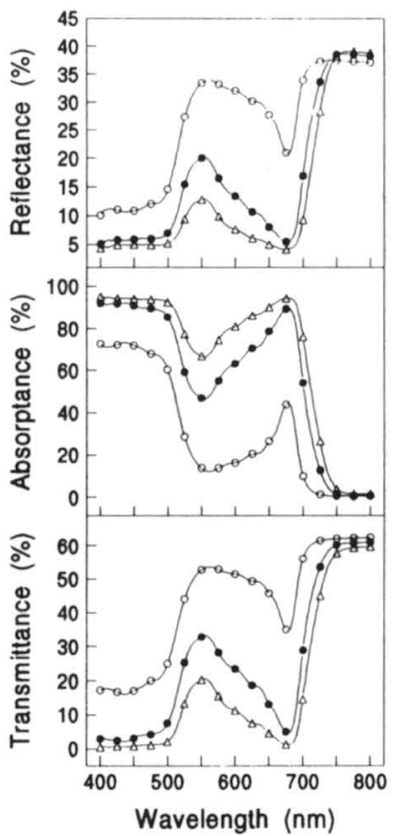

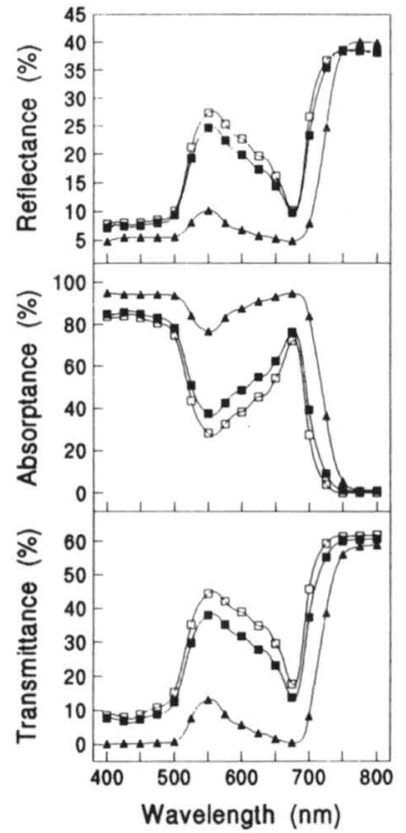

Fig. 2. Spectra of $\mathbf{R}, \mathbf{A}$, and $\mathbf{T}$ of the youngest fully expanded leaf of corn. Legend: open triangles, normal-1 plants (4-leaf stage); solid triangles, normal-2 plants (5-leaf stage); open circles, Fe; solid circles, $\mathrm{S}$; open squares, $\mathrm{Mg}$; solid squares, $\mathrm{Mn}$.

(1992), they were closely correlated with one another and with the integrated value over the entire 400- to 700 -nm range (results not shown). Thus, values at these wavelengths are representative of the entire visible wavelength region.

All growth-medium mineral deficiencies caused pronounced modifications in leaf $\mathrm{A}, \mathrm{R}$, and $\mathrm{T}$ spectra in the visible region. The lowest variations produced by mineral deficiencies were recorded at wavelengths shorter than $500 \mathrm{~nm}$ and at $678 \mathrm{~nm}$; the greatest variations recorded were near 555 and $700 \mathrm{~nm}$. Figure 4 shows (for all species) the absolute difference between $\mathrm{R}, \mathrm{A}$, and $\mathrm{T}$ of leaves grown under normal and mineral-deficient growth medium conditions at $555 \mathrm{~nm}$ and $678 \mathrm{~nm}(555$ $\mathrm{nm}$ being the wavelength of maximum variation among treatments and $678 \mathrm{~nm}$ being the wavelength of maximum in vivo Chl absorption). At $555 \mathrm{~nm}$, all mineral deficiencies reduced $\mathrm{A}$ and increased $\mathrm{R}$ and $\mathrm{T}$. Iron deficiency in the growth medium caused a marked decrease in leaf $\mathrm{A}$ in all species; in corn, the decrease was $54 \%$, and in wheat and sunflower it was nearly $40 \%$. With the other mineral deficiencies, leaf $\mathrm{A}$ decreased differently from species to species. The greatest reduction in leaf A was induced in barley and wheat by S deficiency and in corn and sunflower by $\mathrm{Mg}$ deficiency, while the smallest reduction was induced in barley and wheat by Mn deficiency and in corn and sunflower by S deficiency. Reflectance increased by a smaller percentage than $\mathrm{T}$ in all species and nutrient deficiencies, with the exception of the Mn-deficient barley leaf and $\mathrm{Mg}$ - and Mn-deficient wheat leaves. At $678 \mathrm{~nm}$, where maximum Chl radiation absorption occurred, deficiency-induced modifications of $\mathrm{R}, \mathrm{A}$, and $\mathrm{T}$ were smaller than at $555 \mathrm{~nm}$, with the

\section{Sunflower}
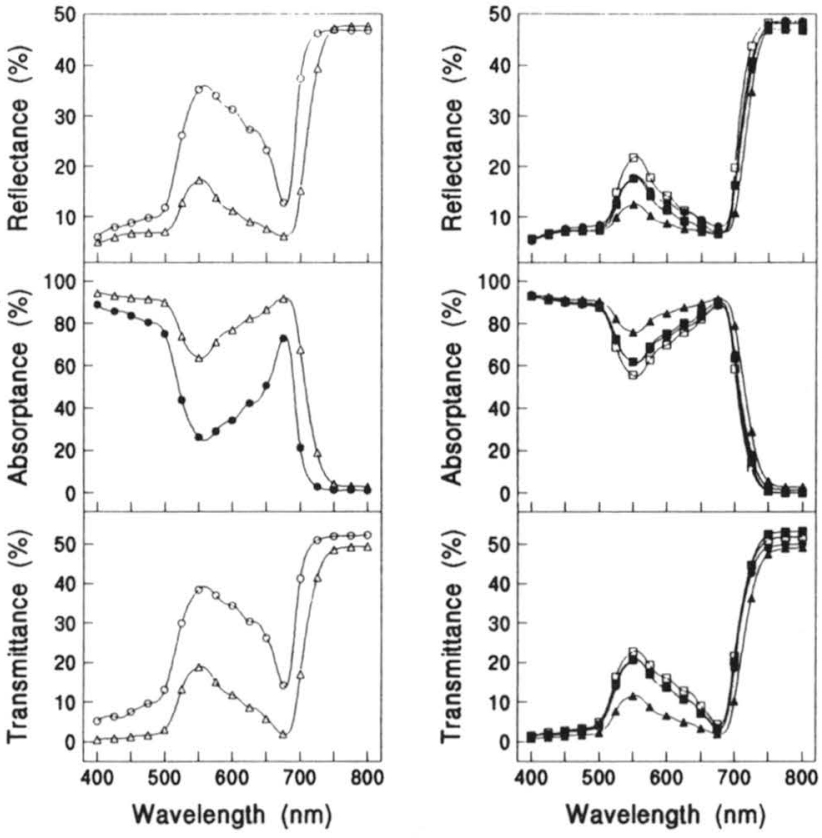

Fig. 3. Spectra of $\mathbf{R}, \mathbf{A}$, and $\mathbf{T}$ of the youngest fully expanded leaf of sunflower. Legend: open triangles, normal-1 plants (Stage V4); solid triangles, normal-23 plants (Stages V10 and R1 pooled); open circles, Fe; solid circles, S; open squares, Mg; solid squares, Mn. Spectra of normal plants in Stages V10 and R1 were averaged because only very slight differences occurred.

exception of corn grown in Fe-deficient growth medium, which showed similar modifications at 555 and $678 \mathrm{~nm}$.

No differences in leaf $\mathrm{A}, \mathrm{R}$, and $\mathrm{T}$ between plants grown under normal and mineral-deficient conditions were observed in the NIR region (data not shown).

Leaf spectral properties at $429,555,678$, and 700 $\mathrm{nm}$ were not correlated with mineral concentrations in leaves. This is consistent with the findings of Labovitz et al. (1983) and Milton et al. (1991). Milton et al. (1991) suggested an indirect effect of deficiency on plant $\mathrm{R}$, hypothesizing an inhibition of nutrient or water uptake. Our data confirmed depleted uptake of other minerals in addition to the deficient mineral and indicated that reduction in leaf nutrient concentration reduced $\mathrm{Chl}$ formation. In all species, the first effect of each mineral deficiency was a reduction in leaf $\mathrm{Chl}$ concentration and consequently a decrease in $\mathrm{A}$ and an increase in $\mathrm{R}$ and T. A curvilinear relationship between leaf $\mathrm{Chl} a$ and $b$ concentration and $\mathrm{A}, \mathrm{R}$, and $\mathrm{T}$ at $429,555,678$, and $700 \mathrm{~nm}$ and in the entire visible region was observed, irrespective of deficiency and species. Relations between spectral properties at $429,555,678$, and $700 \mathrm{~nm}$ and in the visible region and leaf $\mathrm{Chl} a$ and $b$ concentration were always significant at 0.01 probability level (Table 4).

In agreement with Buschmann and Nagel (1993), in the visible region the best correlation between leaf $\mathrm{Chl}$ concentration and $\mathrm{R}, \mathrm{T}$, and $\mathrm{A}$ was recorded at 555 and $700 \mathrm{~nm}$. Variations at these wavelengths were of the same amount and were the greatest in the spectra. At $555 \mathrm{~nm}$, when Chl $a$ concentration increased from 23 to $479 \mu \mathrm{mol} \mathrm{m} \mathrm{m}^{-2}$, $\mathrm{R}$ decreased from 34 to $13 \%, \mathrm{~T}$ decreased from 51 to $12 \%$, and $\mathrm{A}$ increased from 15 


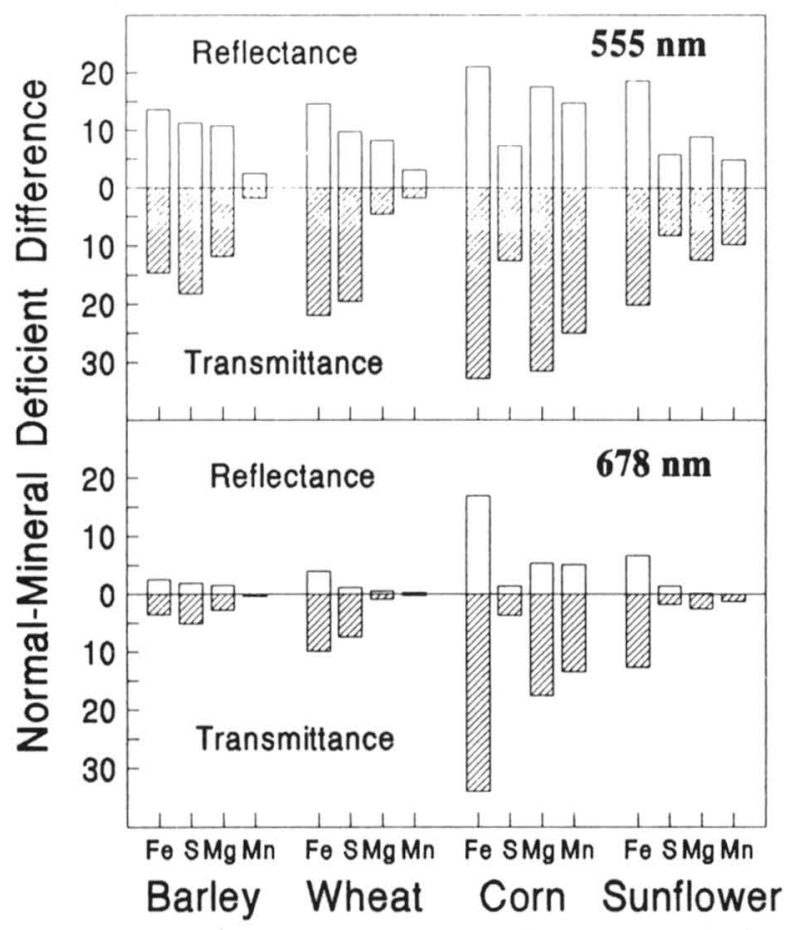

Fig. 4. Absolute difference (percent) of mean $R$ and $T$ between nutrient deficient and normal leaves of barley, wheat, corn, and sunflower at 555 and $678 \mathrm{~nm}$. Values are means of a 10-nm waveband centered on 555 and $678 \mathrm{~nm}$. The area between percent $R$ and $T$ is percent A. Mean R, A, and T of the mineral-deficient leaf differed from its control except for the $\mathrm{Mn}$-deficient leaf in barley and the $\mathrm{Mg}$ and Mn-deficient leaves in wheat and in sunflower.

to $76 \%$ (Fig. 5). Although $\mathrm{R}$ is the spectral property commonly utilized in remote sensing, A may be the most suitable spectral property for detecting small variations produced by changes in leaf physiologic characteristics, such as those due to nutrient deficiency, because the range of variability of $A$ is higher than that of $\mathrm{R}$ or $\mathrm{T}$.

\section{Red-Edge Position}

Red-edge position will be discussed only in R spectra, since it varied by only 2 to $3 \mathrm{~nm}$ among R, A, and T spectra (Table 5). All nutrient deficiencies produced a shift in red-edge position to shorter wavelengths, but this shift was found to differ among species. Red-edge shifts of more than $17 \mathrm{~nm}$ were observed for corn grown

Table 4. Correlation coefficients between leaf spectral properties at $429,555,678$, and $700 \mathrm{~nm}$ and in the visible region (PAR) $(400-700 \mathrm{~nm})$ and leaf chlorophyll (Chl) $a$ and $b$ concentration.

\begin{tabular}{|c|c|c|c|c|c|}
\hline \multirow[b]{2}{*}{ Chl } & \multirow[b]{2}{*}{ PAR } & \multicolumn{4}{|c|}{ Leaf spectral properties (by wavelength, $\mathrm{nm}$ ) } \\
\hline & & 429 & 555 & 678 & 700 \\
\hline & \multicolumn{5}{|c|}{ Reflectance (R) } \\
\hline$a$ & $0.908^{* *}$ & $0.644 * *$ & $0.903^{* *}$ & $0.904^{* *}$ & $0.903^{* *}$ \\
\hline \multirow[t]{2}{*}{$b$} & $0.866^{* *}$ & $0.555^{* *}$ & $0.904 * *$ & $0.664^{* *}$ & $0.891^{* *}$ \\
\hline & \multicolumn{5}{|c|}{ Absorptance (A) } \\
\hline$a$ & $0.978^{* *}$ & $0.927 * *$ & $0.985^{* *}$ & $0.960^{* *}$ & $0.979^{* *}$ \\
\hline \multirow[t]{2}{*}{$b$} & $0.888^{* *}$ & $0.720^{* *}$ & $0.939 * *$ & $0.745^{* *}$ & $0.925^{* *}$ \\
\hline & \multicolumn{5}{|c|}{ Transmittance $(\mathrm{T})$} \\
\hline$a$ & $0.974 * *$ & $0.937 * *$ & $0.977 * *$ & $0.963^{* *}$ & $0.981 * *$ \\
\hline$b$ & $0.863^{* *}$ & $0.708 * *$ & $0.904^{* *}$ & $0.760^{* *}$ & $0.904 * *$ \\
\hline
\end{tabular}

** Model significant at the 0.01 probability level $(F$-test).

$\dagger$ The model used was $y=a[1+b \exp (-k x)]$, where $x=C h l$ concentration,

$y=\mathrm{R}, \mathrm{A}$, or $\mathrm{T}$ at each wavelength, and $a, b$, and $k$ are constants.
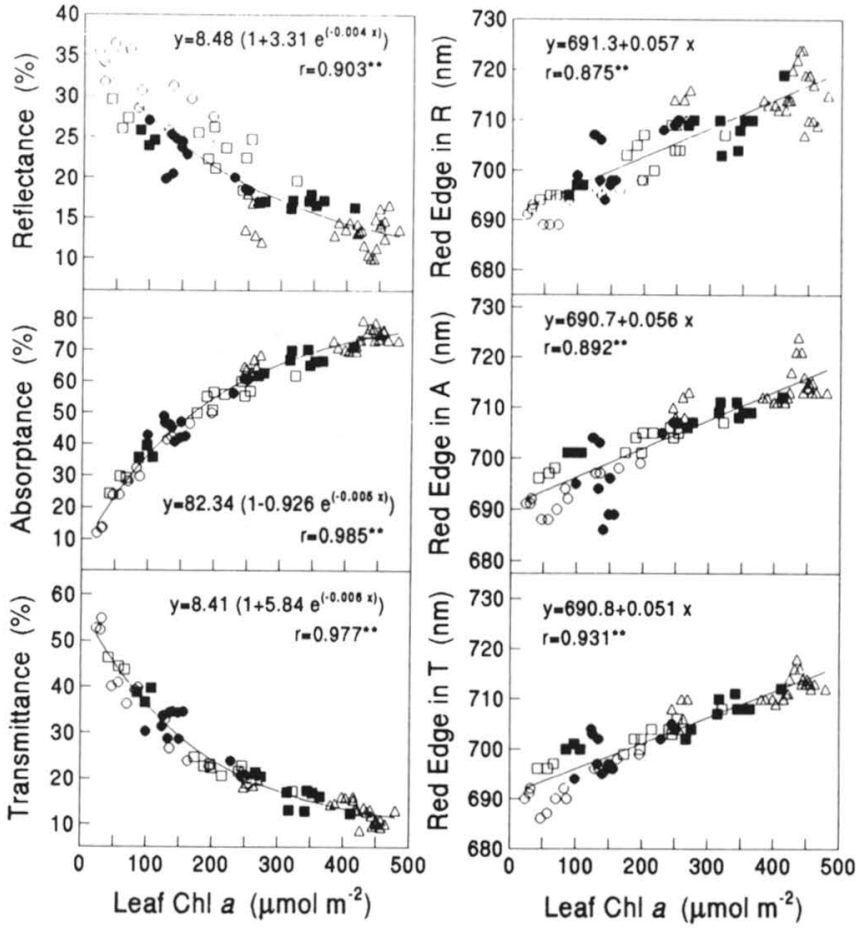

Fig. 5. Relationships between leaf $\mathrm{Chl} a$ concentration and leaf $\mathbf{R}$, $A$, and $T$ at $555 \mathrm{~nm}$ (values are means of a $10-\mathrm{nm}$ waveband centered on $555 \mathrm{~nm}$ ) and between leaf $\mathrm{Chl} a$ concentration and red-edge position in $\mathbf{R}, \mathbf{A}$, and $\mathrm{T}$ spectra. Legend: open triangles, normal plants; open circles, $\mathrm{Fe}$; solid circles, $\mathrm{S}$; open squares, $\mathrm{Mg}$; solid squares, Mn.

with $\mathrm{Fe}-\mathrm{Mg}$-, and $\mathrm{Mn}$-deficient growth media, for barley and wheat with $\mathrm{Fe}$ - and S-deficient media, and for sunflower with the Fe-deficient medium. In wheat and barley, Mn deficiency shifted the red-edge position by only 3 to $4 \mathrm{~nm}$. No correlation was observed between red-edge position and leaf $\mathrm{Fe}, \mathrm{S}, \mathrm{Mg}$, and $\mathrm{Mn}$ concentration. Thus, red-edge position allowed separation by neither species nor mineral deficiency. Red-edge position was linearly correlated with leaf Chl $a$ concentration, irrespective of spectral properties, species, or mineral deficiencies. Increasing leaf $\mathrm{Chl} a$ concentration shifted red-edge position in $\mathrm{R}$ spectra to longer wavelengths with an increase of $57 \mathrm{~nm}$ per mmol Chl $a \mathrm{~m}^{-2}$ (Fig. 5).

\section{CONCLUSIONS}

Nutritional stress caused first a decrease in leaf chlorophyll concentration and subsequently a decrease in absorptance, and it caused an increase in reflectance and transmittance, and shifted the red-edge position to shorter wavelengths. For the crop species tested, variations in spectral properties and red-edge position were proportional to stress level and leaf $\mathrm{Chl}$ concentration, and were observed in the same spectral wavelength.

In barley, wheat, corn, and sunflower, mineral deficiency affected leaf concentration of the deficient element and other elements, with percent variation differing according to species and deficiency. Modifications of leaf spectral properties were not produced by or characteristic of only one deficient element but rather the combined result of several deficient elements.

Many variations in spectral properties can occur, depending also on the interaction between deficiency of a 
Table 5. Red-edge position of $\mathbf{R}, \mathrm{A}$, and $\mathrm{T}$ spectra of the youngest fully expanded leaf of barley, wheat, corn, and sunflower plants grown under normal and Fe-, S-, Mg-, and Mn-deficient conditions. For each species and deficiency, comparison was made between leaves grown under normal and mineral deficient conditions. The position in normal plants differs among elements because of time of sampling.

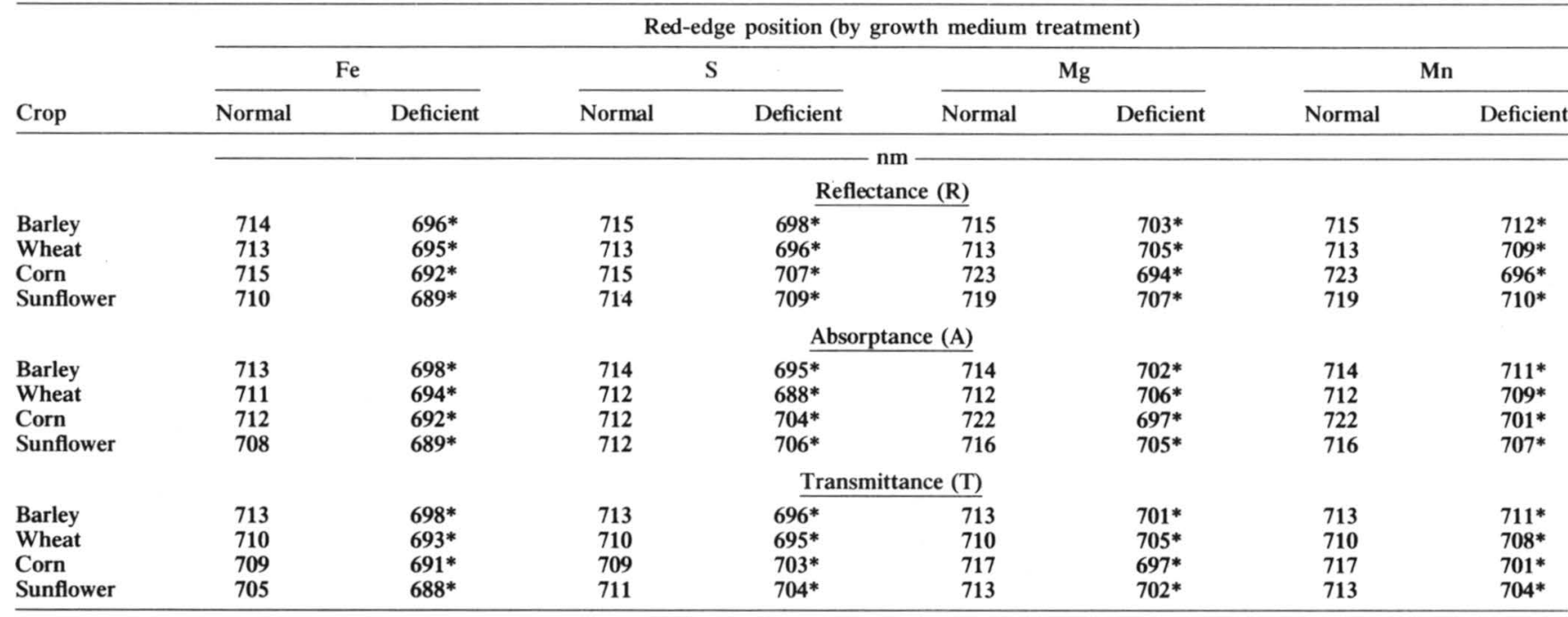

* Significant at the 0.05 probability level $(F$-test).

given mineral and level of deficiency. In wheat, for instance, the same leaf $\mathrm{Chl}$ concentration, or leaf $\mathrm{R}$, or red-edge position can be found with a slight Fe deficiency as with a severe $\mathrm{Mg}$ deficiency. Therefore, measurements of spectral properties are utilizable for detecting mineral deficiencies in field crops only if both plant species and specific nutrient deficiency are known. In conclusion, measurements of spectral properties of attached leaves may be very interesting for early, easy, and inexpensive determination of mineral deficiencies or other stress conditions (i.e., water stress), only when the species and the deficiency are known a priori.

\section{REFERENCES}

Adams, M.L., W.A. Norvell, J.H. Peverly, and W.D. Philpot. 1993. Fluorescence and reflectance characteristics of manganese deficient soybean leaves: effect of leaf age and choice of leaflet. Plant Soil 155/156:235-238.

Al-Abbas, A.H., R. Barr, J.D. Hall, F.L. Crane, and M.F. Baumgardner. 1974. Spectra of normal and nutrient-deficient maize leaves. Agron. J. 66:16-20.

Berg, W.A., M.E. Hodges, and E.G. Krenzer. 1993. Iron deficiency in wheat grown on the southern plains. J. Plant Nutr. 16:12411248.

Blackmer, T.M., J.S. Schepers, and G.E. Varvel. 1994. Light reflectance compared with other nitrogen stress measurements in corn leaves. Agron. J. 86:934-938.

Buschmann, C., and E. Nagel. 1993. In vivo spectroscopy and internal optics of leaves as basis for remote sensing of vegetation. Int. J. Remote Sens. 4:711-722.

Chappelle, E.W., M.S. Kim, and J.E. McMurtrey. 1992. Ratio analysis of reflectance spectra (RARS): An algorithm for the remote estimation of the concentrations of chlorophyll $a$, chlorophyll $b$, and carotenoids in soybean leaves. Remote Sens. Environ. 39: 239-247.

Clark, R.B. 1982. Nutrient solution growth of sorghum and corn in mineral nutrition studies. J. Plant Nutr. 5:1039-1057.

Ercoli, L., M. Mariotti, A. Masoni, and F. Massantini. 1993. Relationship between nitrogen and chlorophyll content and spectral properties in corn leaves. Eur. J. Agron. 2:113-117.

Gausman, H.W., W.A. Allen, D.E. Escobar, R.R. Rodriguez, and R. Cardenas. 1971. Age effects of cotton leaves on light reflectance, transmittance, and absorptance and on water content and thickness. Agron. J. 63:465-469.
Gausman, H.W., and W.A. Allen. 1973. Optical parameters of leaves of 30 plant species. Plant Physiol. 52:57-62.

Gausman, H.W. 1982. Visible light reflectance and absorptance of differently pigmented cotton leaves. Remote Sens. Environ. 13: 233-238.

Hanway, J.J. 1963. Growth stages of corn (Zea mays L.). Agron. J. 55:487-492.

Hafez, A.A., S.S. Goyal, and D.W. Rains. 1991. Quantitative determination of total sulfur in plant tissues using acid digestion and ion-chromatography. Agron. J. 83:148-153.

Horler, D.N.H., M. Dockray, and J. Barber. 1983. The red-edge of plant leaf reflectance. Int. J. Remote Sens. 2:273-288.

Labovitz, M.L., E.J. Masuoka, R. Bell, A.W. Siegrist, and R.F. Nelson. 1983. The application of remote sensing to geobotanical exploration for metal sulfides: Results from the 1980 field season at Mineral, Virginia. Econ. Geol. 4:750-760.

Maas, S.J., and J.R. Dunlap. 1989. Reflectance, transmittance, and absorptance of light by normal, etiolated, and albino corn leaves. Agron. J. 81:105-110.

Milton, N.M., C.M. Ager, B.A. Eiswerth, and M.S. Power. 1989. Arsenic- and selenium-induced changes in spectral reflectance and morphology of soybean plants. Remote Sens. Environ. 30:263269.

Milton, N.M., B.A. Eiswerth, and C.M. Ager. 1991. Effect of phosphorus deficiency on spectral reflectance and morphology of soybean plants. Remote Sens. Environ. 36:121-127.

Moran, R. 1982. Formulae for determination of chlorophyllous pigments extracted with $N, N$-dimethylformamide. Plant Physiol. 69: 1376-1381.

Nielsen, D.L., B.L. Blad, S.B. Verma, N.J. Rosenberg, and J.E. Specht. 1984. Influence of soybean pubescence type on radiation balance. Agron. J. 76:924-928.

Ohki, K. 1984. Manganese deficiency and toxicity effects on growth, development, and nutrient composition in wheat. Agron. J. 76: 213-218.

Savitzky, A., and M.J.E. Golay. 1964. Smoothing and differentiation of data by simplified least square procedures. Anal. Chem. 35: 1627-1639.

Schneiter, A.A., and J.F. Miller. 1981. Description of sunflower growth stages. Crop Sci. 21:901-903.

Thomas, J.R., and G.F. Oerther. 1972. Estimating nitrogen content of sweet pepper leaves by reflectance measurements. Agron. J. 64:11-13.

Walburg G., M.E. Bauer, C.S.T. Daughtry, and T.L. Housley. 1982. Effect of nitrogen nutrition on growth, yield and reflectance characteristics of corn canopies. Agron. J. 74:677-683.

Zadoks, J.C., T.T. Chang, and C.F. Konzak. 1974. A decimal code for the growth stages of cereals. Weed Res. 14:415-421 